\title{
Peculiarities of Predicted
}

\section{Temperature Dependence of}

Nanometer Particle Mobilities

\section{Hannes Tammet}

Department of Environmental Physics,

\author{
Tartu University, \\ Tartu, Estonia EE2400
}

- The model of the size-mobility relation Tammet, H. (1995) Size and mobility of nanometer particles, clusters and ions, J. Aerosol Sci. 26, 459-475.

- Temperature variation of the mobility according to the model.

- Peculiarities of the temperature variation.

- Importance of the law of temperature variation of the mobility. 
Diffusion coefficient Mechanical mobility

$$
D=k T B
$$

\section{Boltzmann constant}

\section{Temperature}

$$
K=q B
$$

\section{Electrical mobility Particle charge}




\section{Well-known facts:}

- A collision between a gas molecule and another molecule or small cluster is elastic-specular.

- A collision between a gas molecule and a macroscopic body (particle) is inelastic.
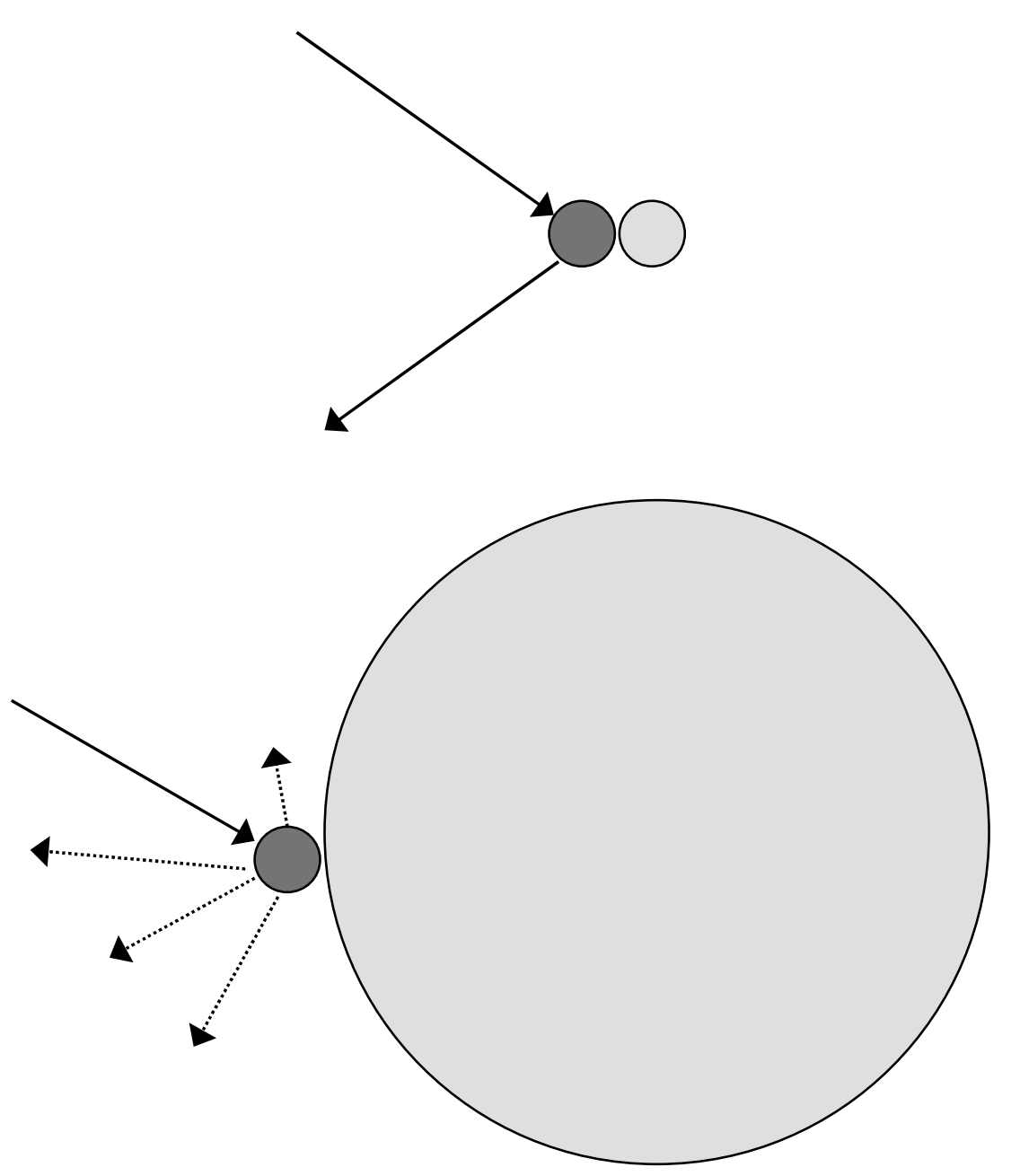

- The mobility of a particle depends on the character of collisions.

\section{See:}

Annis, B.K., Malinauskas, A.P., and Mason, E.A. (1972)

Theory of drag on neutral or charged spherical aerosol particles.

J. Aerosol Sci. 3, 55-64. 


\section{Transition from elastic to inelastic collisions (nanometer size range)}

Formal mathematical approximations:

(1) Tammet, H. (1988) Proc. 8th Int. Conf. Atmos. Electricity, Uppsala, pp. 21-30.

(2) Ramamurthi, M. and Hopke, P.K. (1989) Health Physics 56, 189-194.

Physical hypothesis:

(3) Tammet, H. (1995) J. Aerosol Sci. 26, 459-475.

Indirect experimental data:

Kilpatrick, W.D. (1971) An experimental massmobility relation for ions in air at atmospheric pressure. Proc. 19th Annu. Conf. Mass Spectrosc., pp. 320-325.

$$
d_{m}=\sqrt[3]{\frac{6 m}{\pi \rho}} \quad r_{m}=\frac{d_{m}}{2}
$$




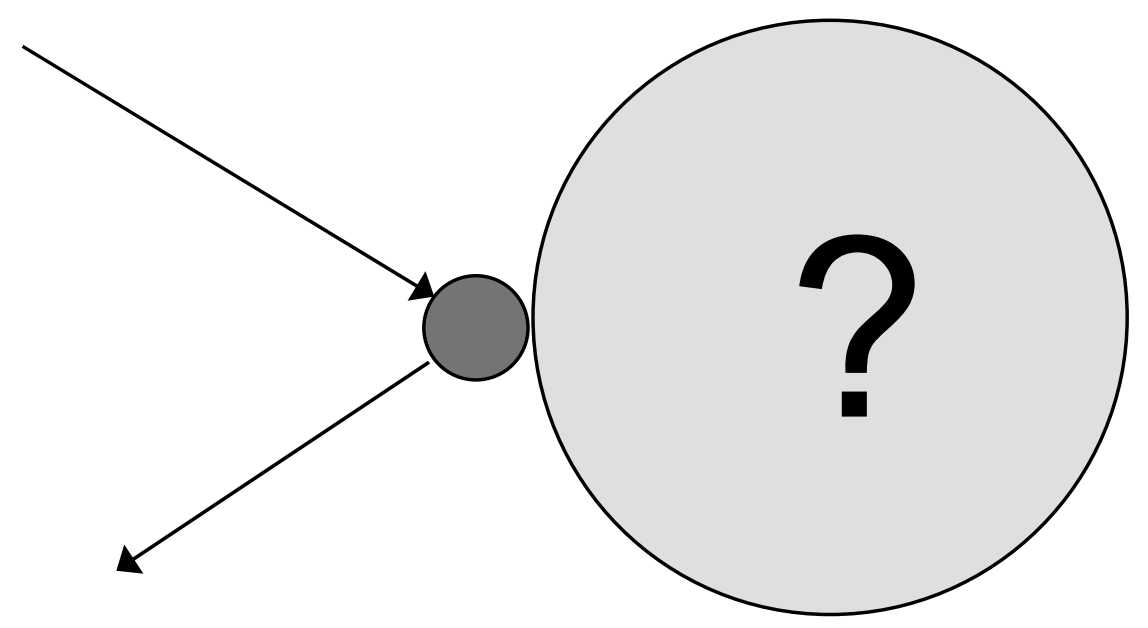

The Einstein factor of melting of the internal degrees of freedom:
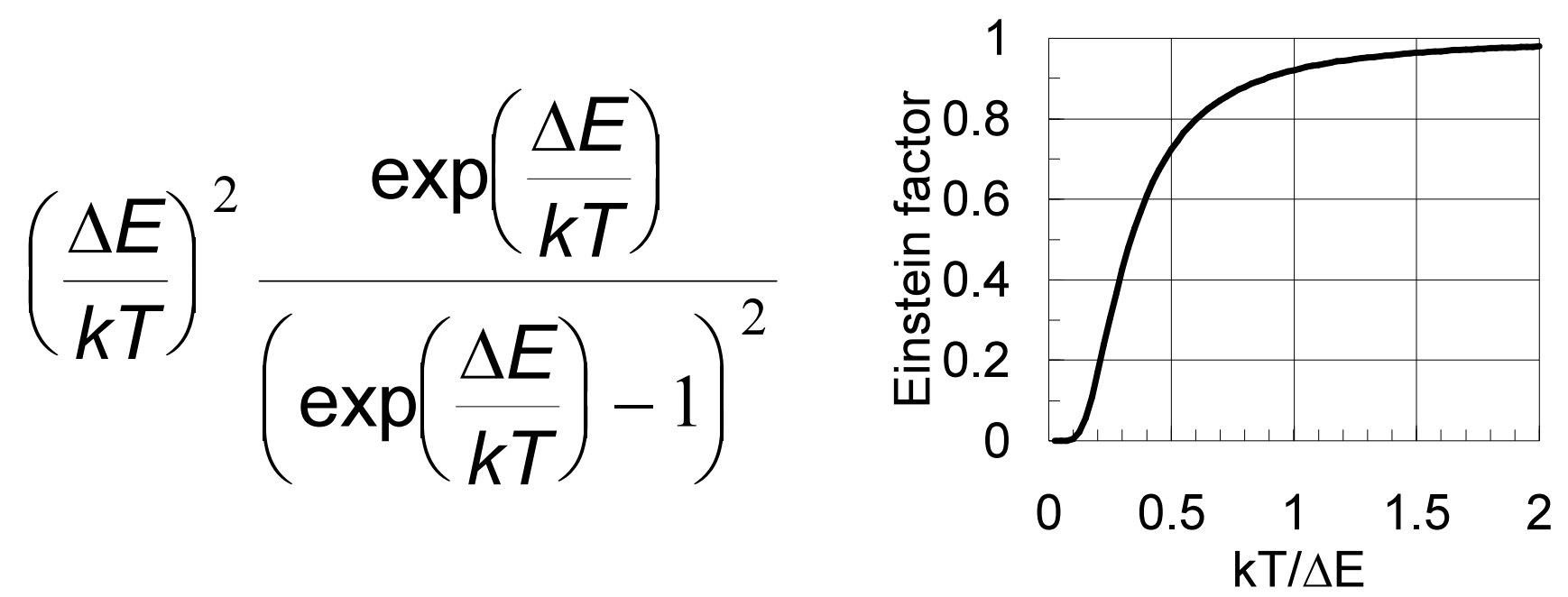

$\Delta E$ - separation of the internal energy levels, $N$ - number of atoms in the particle, $d_{m}$ and $r_{m}$ - mass diameter and mass radius.

$$
d_{m}=\sqrt[3]{\frac{6 m}{\pi \rho}} \quad r_{m}=\frac{d_{m}}{2} \quad \overline{\Delta E}=\frac{\text { const }_{1}}{N}=\frac{\text { const }_{2}}{r_{m}^{3}}
$$




\section{Importance:}

1) verification of the model,

2) reduction of the mobilities,

3) distinction between particles and clusters.

\section{Langevin reduction used by Kilpatrick:}

$K_{\text {reduced }}=K_{\text {measured }} \frac{273.15 \mathrm{~K}}{T} \frac{p}{101325 \mathrm{~Pa}}$

$K \approx\left(\sqrt[3]{\frac{850 \mathrm{u}}{m}}-0.3\right) \mathrm{cm}^{2} \mathrm{~V}^{-1} \mathrm{~s}^{-1}$

CRC Handbook of Physics and Chemistry (1993), 74th edition.

\section{Corrected reduction:}

$K_{\text {measured }} \rightarrow d_{m} \rightarrow K_{\text {reduced }}$

$K \approx\left(\sqrt[3]{\frac{1210 \mathrm{u}}{m}}-0.21\right) \mathrm{cm}^{2} \mathrm{~V}^{-1} \mathrm{~s}^{-1}$ 


\section{Distinction between \\ MACROSCOPIC PARTICLES and}

\section{MOLECULAR CLUSTERS}

According to the long term measurements of atmospheric ions the mobility of $0.5 \mathrm{~cm}^{2} \mathrm{~V}^{-}$ ${ }^{1} \mathrm{~s}^{-1}$ appears as critical in statistical behavior of air ion fraction concentrations.

The mass diameter of critical air ions 1.6 $\mathrm{nm}$ is just the same as the critical diameter of the transition from elastic to inelastic collisions.

Therefore, the term macroscopic particles could be preferred when speaking about particles of diameter greater than $1.6 \mathrm{~nm}$ and the term molecular clusters when considering the particles of diameter less than $1.6 \mathrm{~nm}$. 



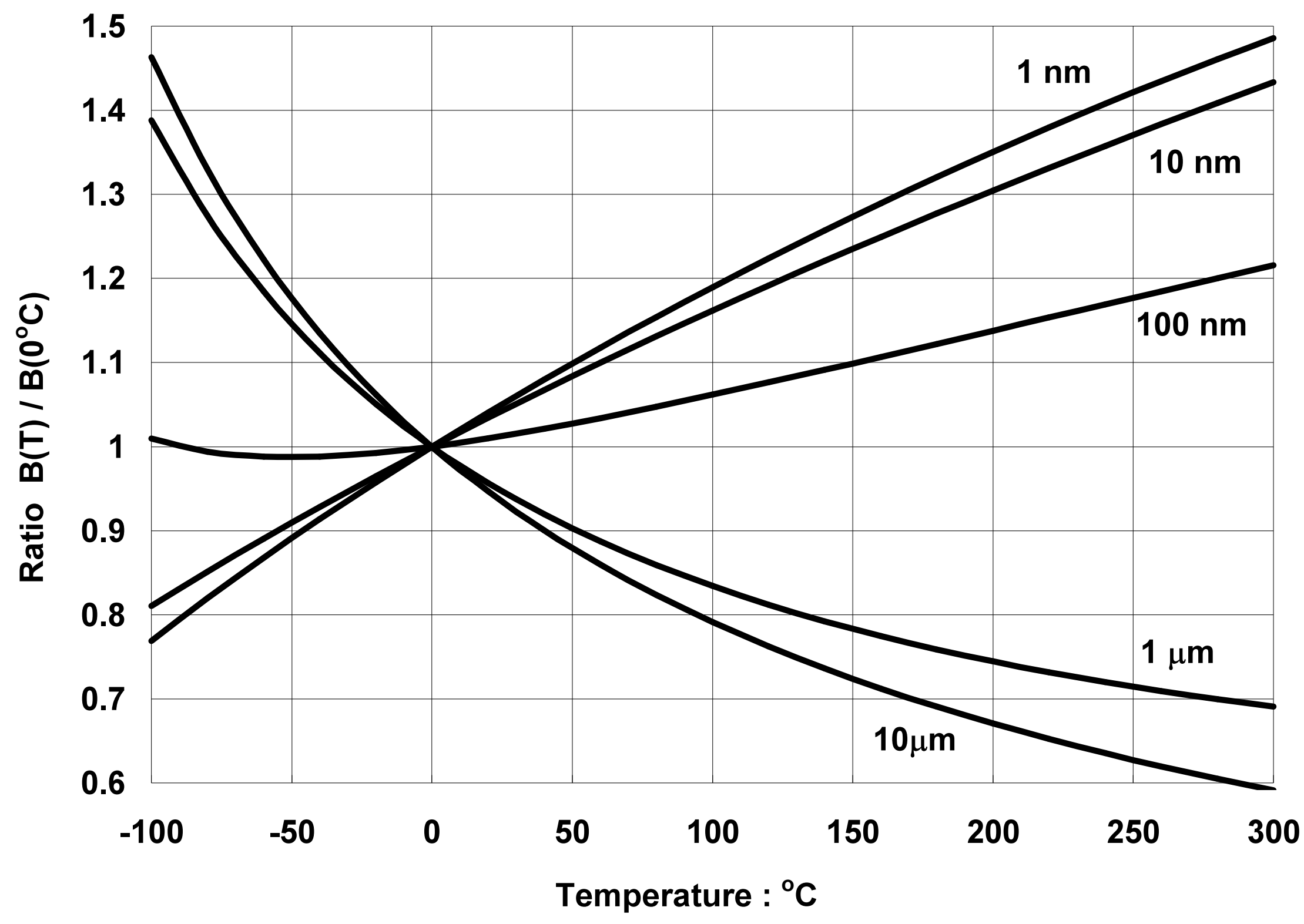




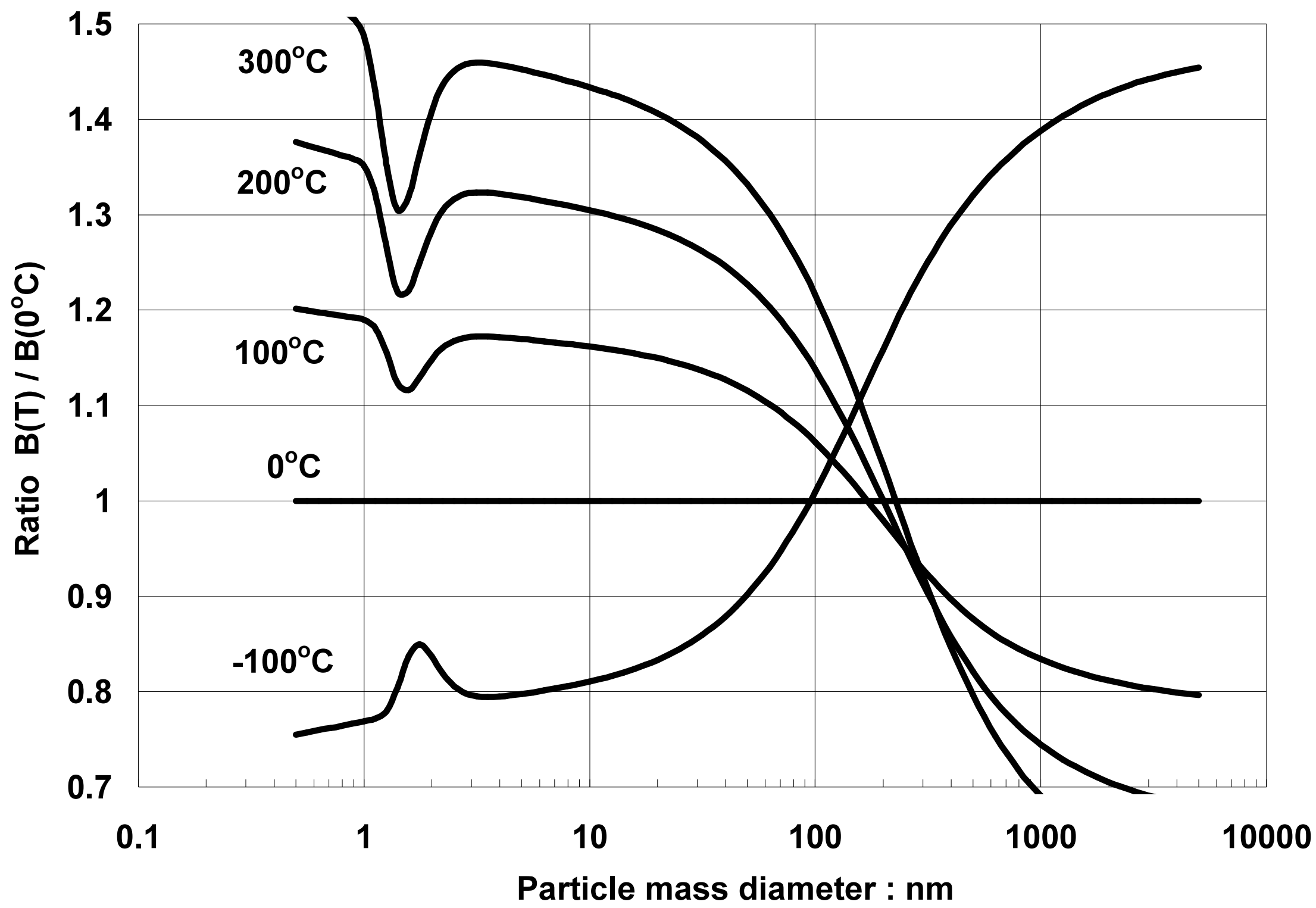




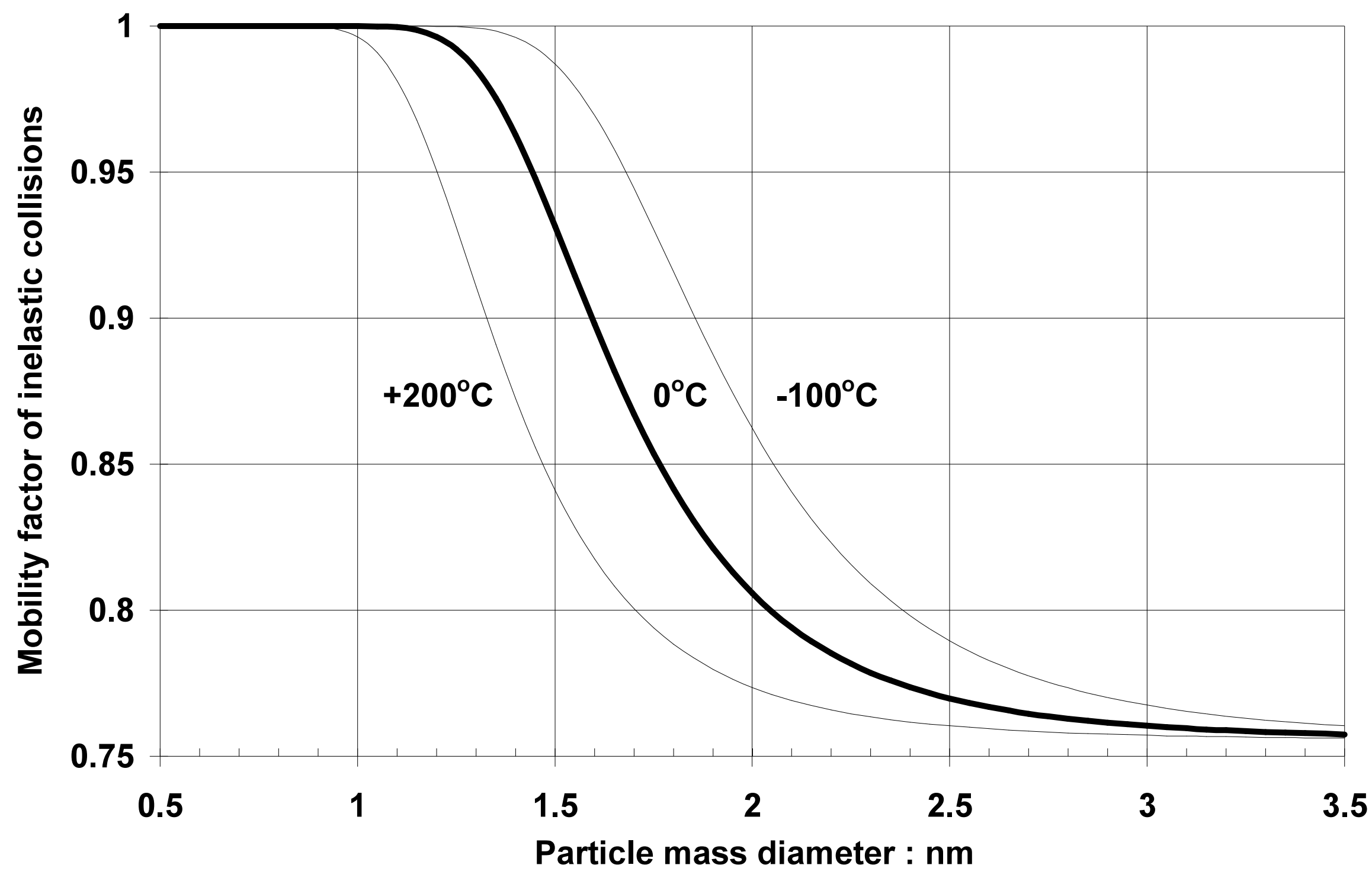




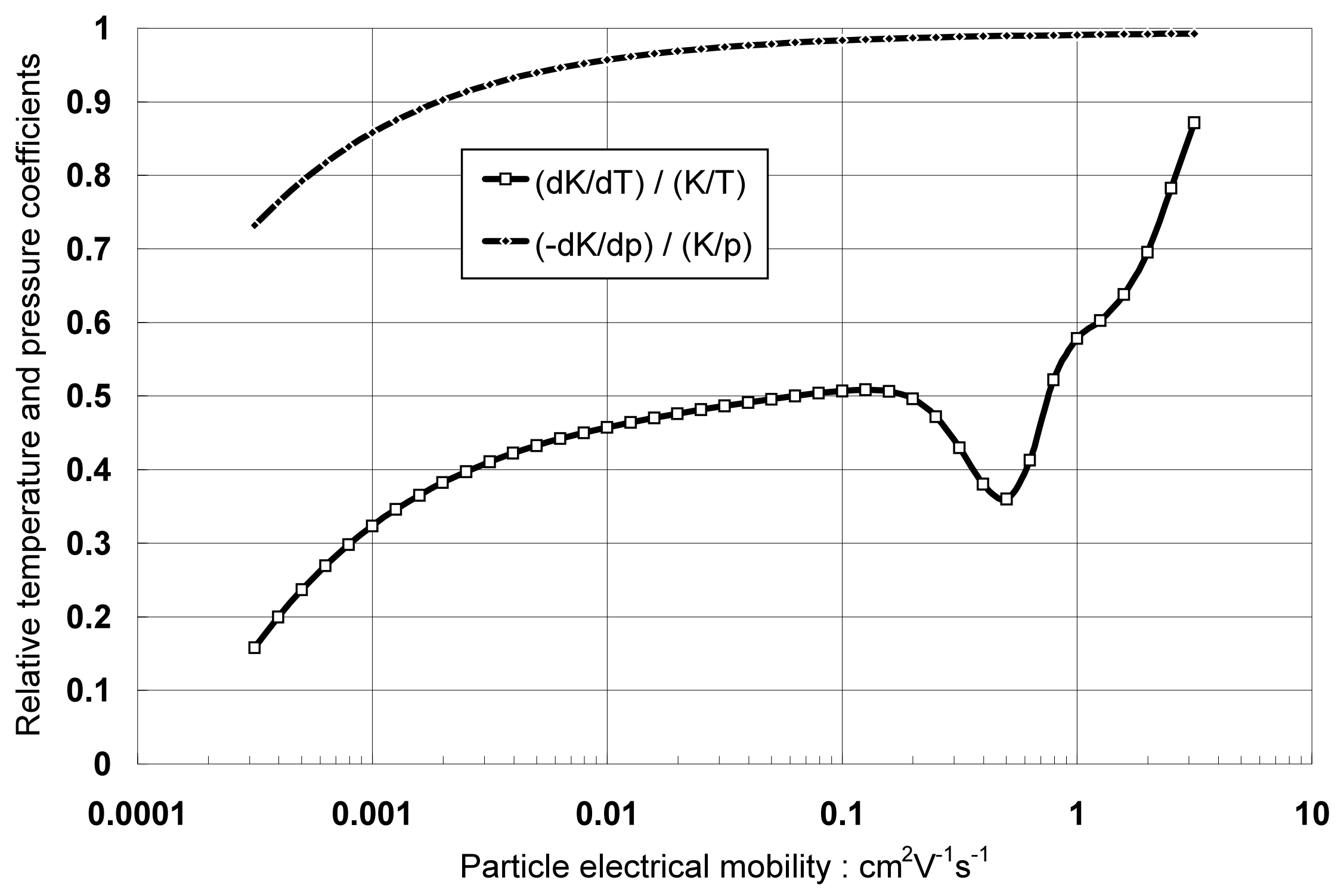




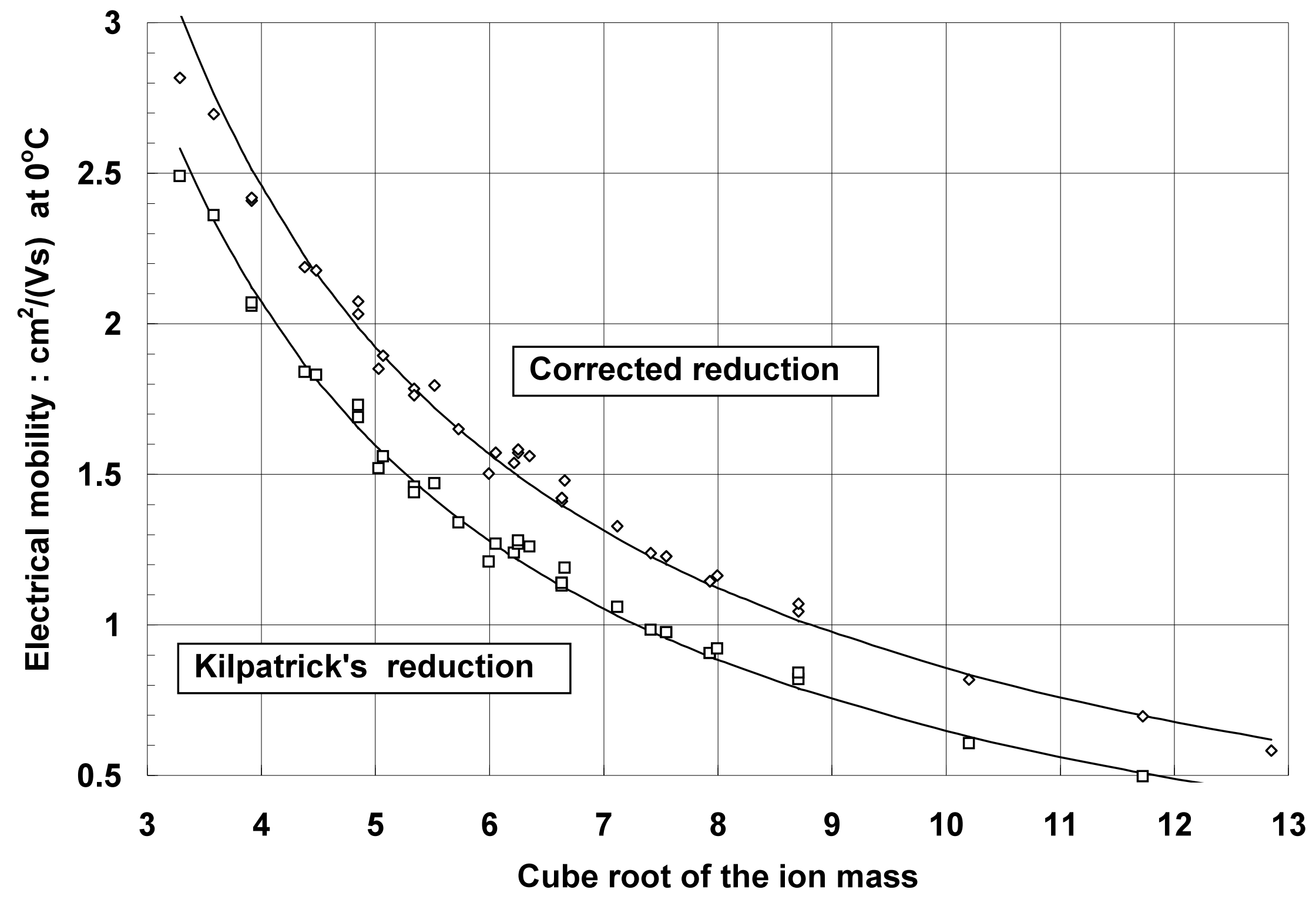




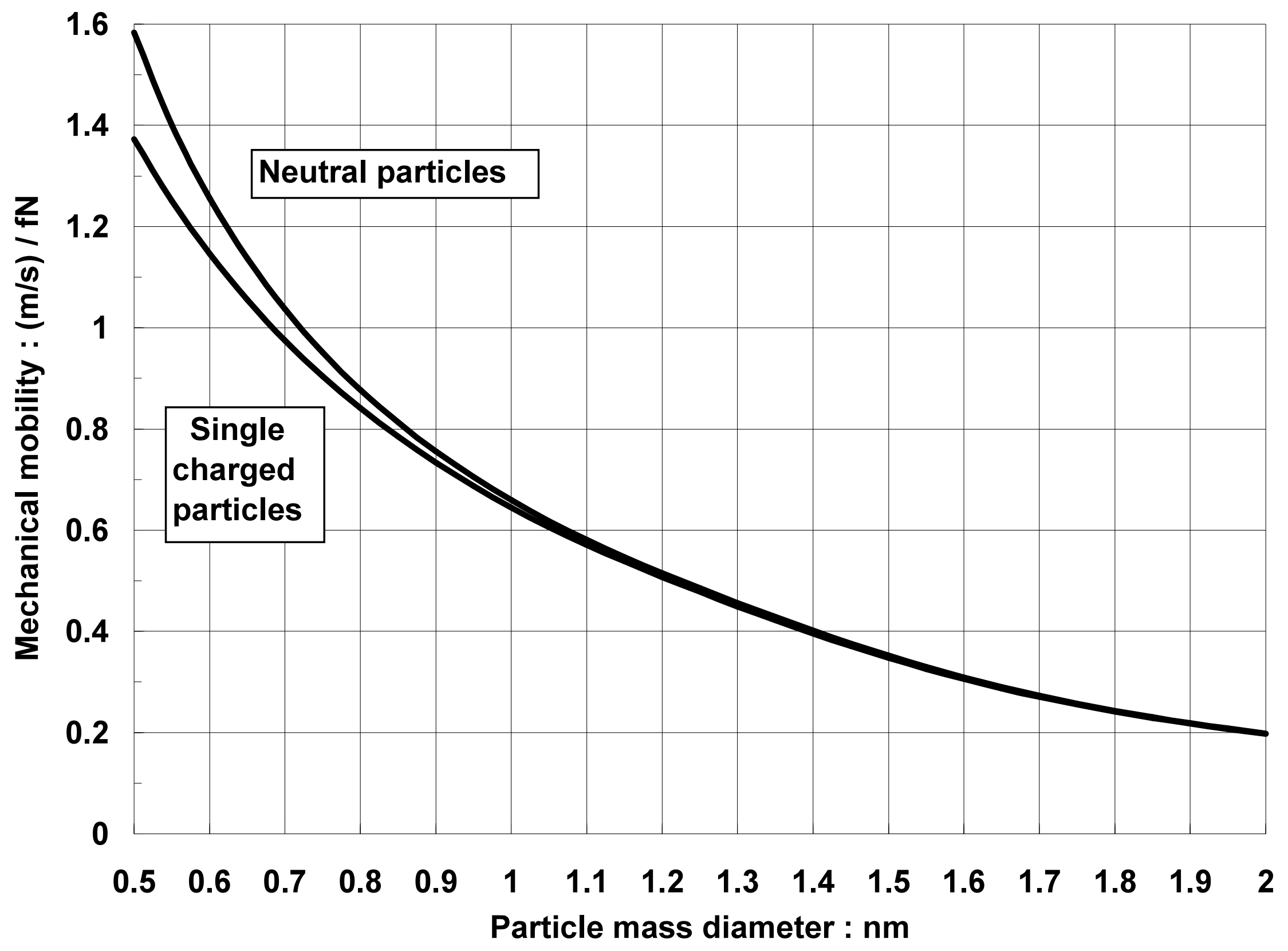

